\title{
Preparation of Porous n-HAp Scaffold Enforced with MWCNTs as Vehicle for Local Drug Delivery of Ciprofloxacin
}

\author{
Gamal S. Albahy' ${ }^{1}$, Y. M. Abbas ${ }^{2}$, A. M. Hezma ${ }^{1}$ and Noha Gweily ${ }^{1, *}$ \\ ${ }^{1}$ Spectroscopy Department, Physics Research Division, National Research Centre, \\ Cairo 12622, Egypt. \\ ${ }^{2}$ Physics Department, Suez Canal University, Ismailia, Egypt.
}

\begin{abstract}
$\mathbf{T}$ HE MAIN objective of this study was synthesis a composite of porous n-HAp/MWCNTs loaded with ciprofloxacin (CFX) as a local drug delivery during surgical procedures with sustained release behavior in the treatment of bone infection minimizing the risks of systemic toxicity. Ciprofloxacin is used as an antibacterial of the Gram-positive and Gramnegative bacteria that affect the bones. The prepared scaffolds loaded with ciprofloxacin were characterized by Fourier transform infrared (FT-IR) spectroscopy, X-ray diffraction (XRD) analysis, Scanning Electron Microscope (SEM) and Cytotoxicity Testing. The in-vitro release of the drug of such scaffolds was also investigated as well as the study of the Entrapment efficiency of scaffold by using U.V spectroscopy. The cytotoxicity of hydroxyapatite containing MWCNTS applied on normal bone cells for the highest rate of $3 \times 10^{-3}$ showed the cell viability greater than $90 \%$. The CFX was successfully loaded within such HAp-nano Scaffolds referred to their reasonable encapsulation efficiencies which they revealed. The drug release behavior showed promising sustained prolonged profiles up to 8 days with minimum initial burst effects.
\end{abstract}

Keywords: Hydroxyapatite; MWCNTs; Ciprofloxacin; Cytotoxicity; Drug Delivery.

\section{Introduction}

The fabrication of implant materials that mimic the structure and properties of human bones remain a challenge among researchers. Due to the biocompatibility, biodegradability and bioactivity certain of biocomposite material based on porous $\mathrm{n}$-HAp matrix was developed as a promising scaffold for the replacement the sick or damaged bone. As multi wall carbon nanotubes, which possessed attention of the world as a candidate for the basic research studies due to its' chemical stability and excellent mechanical properties. Thus, the introduction of multi-walled carbon nanotubes (MWCNTs) into the hydroxyapatite (HAp) matrix was performed in order to improve the performance of the HAp. Resulting porous n-HAp/MWCNTs composites that were considered as good nominee as a study drug carrier for the treatment of bone diseases.

Conventional methods of providing a patient with pharmacological active substances suffer from being very poorly selective, so that damage occurs to the healthy tissues and organs, other than the intended target. In addition, high doses of drugs are necessary to get the desired effect. The use of local drug delivery as rout of administrations is An alternative approach able to release drug in a controlled way[1]. Therefore, the advantages of local antibiotic administration; high local levels with low systemic toxicity are nowadays recognized. Scaffolds are also used as carriers for the delivery of CFX. Porous n-HAp/MWCNTs composites are manufactured as scaffold where MWCNTs play an important role that strengthening the ceramic matrix $[2,3]$. MWCNTs enhanced mechanical properties of HAp materials , propose a possible implantation used for orthopedic applications[2, 4]. In addition, MWCNTs show no significant toxicity when it used as traces. Implant scaffold that attach the cell and make colonization play a crucial role in the construction of extracellular bone to improve the performance of tissues organs. There are precautions of scaffold implant to act as effective tissue organ, it comprises high surface area with convenient pore size, porosity is necessary, and nontoxic scaffold (i.e. Biocompatibility) is a

Corresponding author: Noha Gweily, E-mail: n_gweily@yahoo.com.

(Received 07/06/2020, accepted 14/06/2020)

DOI: $10.21608 /$ jtcps.2020.32002.1041

C2020 National Information and Documentation Centre (NIDOC) 
major requirement for tissue. Biodegradability is commonly needed where the rate of degradation must correspond to the rate of formation of tissues. Mechanical properties must preserve the original formation of tissues. The scaffold implant must preserve a progressive contact with tissue organs including improved cell attachment, migration, propagation and differentiation and act as transporters to achieve growth and differentiation factors.[5, 6]. Composite showed excellent hemocompatibility and inclusion of MWCNTs as traces did not make any negative interaction[2]. Porous n-HAp/MWCNTs composite act as carriers have shown the potential effectiveness of quinolones in local drug delivery systems to treat bone infection $[7,8]$

\section{Materials and Methods}

\section{Materials}

The chemicals used were Calcium Nitrate 4-hydrateGR $\left[\mathrm{CA} \quad\left(\mathrm{NO}_{3}\right)_{2} \cdot 4 \mathrm{H}_{2} \mathrm{O}\right]$ from Alpha chemical with $\mathrm{MW}=236.15$. Ammonium phosphate, dibasic $\left[\left(\mathrm{NH}_{4}\right)_{2} \mathrm{HPO}_{4}\right]$ from NSF with $\mathrm{Mw}=132.06$. Ammonia solution 25\% with $\mathrm{Mw}=17.03$. Poly vinyl Alcohol Extra pure $\left(-\mathrm{C}_{2} \mathrm{H}_{4} \mathrm{O}\right)_{\mathrm{n}}$ from Alpha chemika, India with $\mathrm{Mw}=$ 115000 (lot No. AL6363). Carbon nanotubes, multi-wall (MWCNTs) of diameter $140 \mathrm{~nm}$, Length 7microns from Streem chemical (lot No. B0981067). Ciprofloxacin HCL (lot No. HB00N1208102).

\section{Preparation of porous $n-H A p$}

Porous n-HAp was prepared by using burn out of pore formers. PVA was dissolved in distilled water at $60^{\circ} \mathrm{C}$ for $1 \mathrm{hr}$ using polymer concentrations of $5 \mathrm{wt} \%$, and $20 \mathrm{wt} \%$. 1 gm of prepared $\mathrm{n}-\mathrm{HAp}$ was added to the PVA solution and continues stirring for overnight using a magnetic stirrer in order to get a better distribution. Scaffolds were cast in a petri dish and kept in the oven at $40^{\circ} \mathrm{C}$ for overnight. The resultant powder was collected for different characterization techniques.

\section{Preparation of porous n-HAp/MWCNTs scaffold}

PVA solution was prepared with concentration $10 \mathrm{wt} \%$ in distilled water. Two samples with different concentration of MWCNTs $0.510^{-3} \%$, $310^{-3} \%$ were prepared with PVA solutions under ultrasonic for $1 \mathrm{hr}$ to ensure good distribution of MWCNTs. $1 \mathrm{gm}$ of prepared n-HAp was added to each PVA/MWCNTs solutions for overnight using a magnetic stirrer in order to ensure a better homogenous of n-HAp in PVA/MWCNTs solutions. Scaffolds were cast in a petri dish and kept in the oven at $40^{\circ} \mathrm{C}$ for overnight. All collected samples (HAp/PVA and HAp/PVA/ MWCNTs) were ball milled at $150 \mathrm{rpm}$ to get fine powders and pressured at 60-65 MPa by uniaxial pressing into cylindrical samples of $0.5 \mathrm{~cm}$ diameter forming pellets. Then the prepared pellets were burned out at $500^{\circ} \mathrm{C}$ for $4 \mathrm{hr}$ to obtain porous scaffolds.

\section{Drug loading in vitro}

In order to load drug (CFX) for both porous n-HAP and porous n-HAp/MWCNTs, CFX was dissolved in double distilled water. The concentration of CFX is kept constant (10mg/ $\mathrm{ml})$. The prepared pellets were then added to the drug solution. The samples were placed in a shaker water bath at $37 \mathrm{oC}$ and checked at $30 \mathrm{rpm}$. The concentration of drug solution was measured at $273 \mathrm{~nm}$ by spectroscopic analysis using UVvisible spectroscopy photometer at time intervals, till reaching the maximum-loaded amount of the drug within the discs examined. The drug encapsulation percentage within discs were determined by using the following relationship [9]

$$
\text { Drug encapsulation }(\%)=\frac{\mathrm{A}-\mathrm{B}}{\mathrm{A}} \times 100
$$

where A and B represent the initial and final drug concentration of the aqueous drug solution.

In case of CFX loaded with porous n-HAp with different porosity $(5 \%, 20 \%)$, the resultant pellets were named as $\mathrm{PH} 5 \mathrm{C}$, and $\mathrm{PH} 20 \mathrm{C}$ respectively. In case of porous n-HAp-10 reinforced with MWCNTs with different concentrations (0.510$3 \%, 310-3 \%$ ), the resultant pellets were named as $\mathrm{PHM} 0.5 \mathrm{C}$ and $\mathrm{PHM} 3 \mathrm{C}$ respectively

\section{Follow-up of the ciprofloxacin release}

The in vitro drug release were carried out on the drug loaded discs for both porous n-HAp and porous n-HAp/MWCNTs after subjecting them to a freeze drying (liophilization). And then such discs were immersed in amber glass vials containing a freshly prepared phosphate buffer solution with $\mathrm{pH}(6.8)$ and then placed in a shaker water bath with an adjusted temperature at $37^{\circ} \mathrm{C}$ at different time intervals $(1,2,3,4,6,8,24,48,69,144,192 \mathrm{hrs}$.) $2 \mathrm{ml}$ drug samples were withdrawn from such examined samples and immediately replaced with $2 \mathrm{ml}$ of donor phosphate buffer solution ( $\mathrm{pH}$ 6.8) at each time intervals and for 8 days, in order to estimate the concentration and rate of drug release from drug loaded examined pellets at those particular time periods using UV-visible spectrophotometer at $271 \mathrm{~nm}$. 


\section{Characterization techniques}

Prepared samples were characterized by XRD, Phase analysis was analyzed by the room temperature powder X-ray diffraction using EMPYREAN X-ray diffractometer with monochromatic $\mathrm{Cu} \mathrm{K} \alpha$ radiation of $\lambda=1.5406 \mathrm{~A}^{\circ}$, scan axis Gonio and scan range $(2 \mathrm{q})$ of $4^{\circ}$ to $90^{\circ}$ at $30 \mathrm{~mA}, \quad 45 \mathrm{kV}[10]$ Fourier Transform Infrared Spectroscopy (FTIR) spectroscopy is particularly useful for the identification of chemicals substances that are either organic or inorganic. The term Fourier Transform Infrared Spectroscopy refers to a fairly recent development of the way in which data are collected and transformed from an interference figure into a spectrum. The wavelength range 4000-400 $\mathrm{cm}^{-1}$ using a computerized recording FTIR spectrometer (Mattson5000, USA). Finely powdered samples were mixed with $\mathrm{KBr}$ in the ratio 1:100 for quantitative analysis and the weight. Morphology analysis was examined under SEM Philips apparatus, USA, type QUANTA FEG 250 and Cambridge type 590.

\section{Results and Discussion}

\section{FTIR spectroscopic analysis of CFX}

Fourier transform infrared (FTIR) spectra were recorded using a Bruker Vertex 70V. The FTIR spectrum of ciprofloxacin illustrates, one prominent characteristic peak was found at $3432.67 \mathrm{~cm}^{-1}$ that was assigned to the stretching vibration of the $\mathrm{OH}$ group and intermolecular hydrogen bonding as shown in Figure 1. The peak at $2,923.56 \mathrm{~cm}^{-1}$ was attributed to the $\mathrm{C}-\mathrm{H}$ stretching vibration of the cyclopropyl group. The 1,950-1,460 $\mathrm{cm}^{-1}$ region exhibited FTIR absorption from a broad variety of doublebonded functional groups. The band at 1702.84 $\mathrm{cm}^{-1}$ characterized carbonyl $\mathrm{C}=\mathrm{O}$ stretching of acid. The band at $1625.7 \mathrm{~cm}^{-1}$ was representing quinolones. The peak at $1459.85 \mathrm{~cm}^{-1}$ represents C-O. A strong absorption band at $1267 \mathrm{~cm}^{-1}$ was assigned to C-F bond stretching[11].

FTIR spectroscopic analysis of Porous n-HAp/CFX

The FTIR spectrum of CFX loaded porous n-HAp for different porous of n-HAp is shown in (Figure. 2) Characteristic structural bands of both HAp and CFX were observed for all porous n-HAp/CFX samples. The typical HAp peaks: PO4characteristic bands present at 566, 605, $1091,1146 \mathrm{~cm}-1$ and a sharp peak at $1052 \mathrm{~cm}-1$ confirming the presence of crystallized HAp. In addition, $\mathrm{OH}$ vibrations are observed at 610 and $3432.67 \mathrm{~cm}-1$. The HA powder has carbonate bands $(\mathrm{C}-\mathrm{O})$ present at 874 and $1449 \mathrm{~cm}-1$. The spectrum of CFX-HAp exhibits different patterns. The peak at $1264 \mathrm{~cm}^{-1}$ is attributed to the $\mathrm{C}-\mathrm{F}$ vibration of CFX. The peak at $1626 \mathrm{~cm}-1$ is attributed to quinolones. The peaks at 1580 and $1381 \mathrm{~cm}-1$ are assigned to stretching vibrations of COO- group[12]. The emergence of characteristic peak at $1702 \mathrm{~cm}^{-1}$ indicate a good incorporation of CFX in to porous n- HAp $[13,14]$. Moreover, the maintenance of the IR characteristic beaks for both antibiotic and HAp, emergence characteristic peak of CFX and the absence of new IR beaks confirm that the antibiotic is only dispersed on the HAp surface and are highly masked by the incorporation of the antibiotics by hydrogen bonding to $\mathrm{P}-\mathrm{OH}$ groups with very minute interaction. The corresponding beaks intensities increase with the increase in porous HAp ratio as a result of the drug loading percentage

FTIR spectroscopic analysis of porous n-HAp-

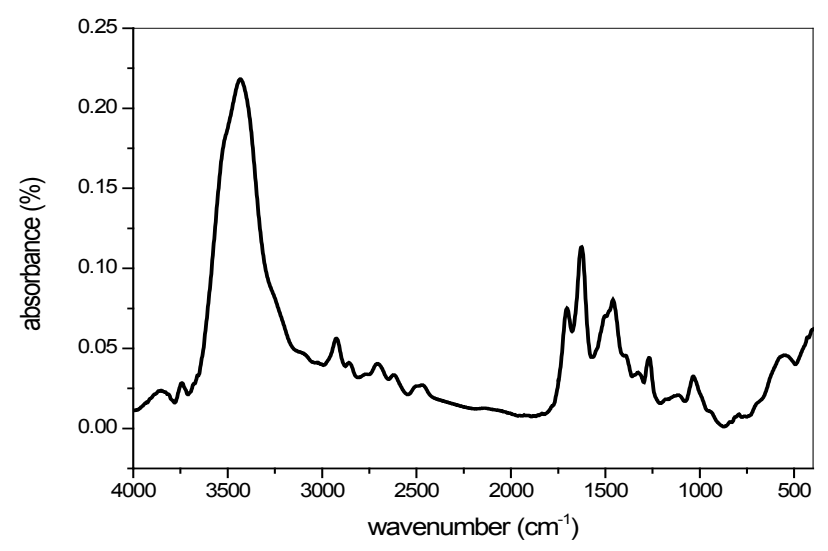

Fig. 1. FTIR of pure ciprofloxacin (CFX) 


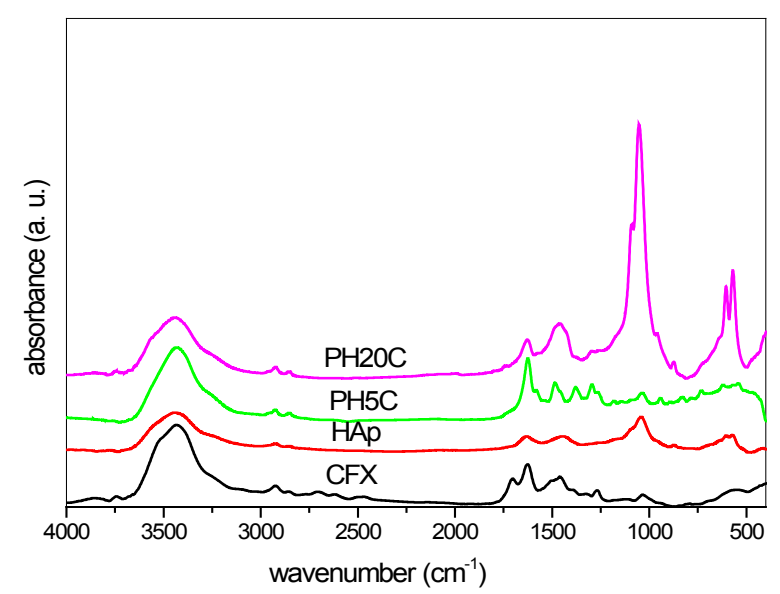

Fig. 2. FTIR spectra of pure ciprofloxacin, pure HAp and porous Hydroxyapatite loaded with ciprofloxacin at various hydroxyapatite ratios (PH5C and $\mathrm{PH} 20 \mathrm{C})$.

\section{MWCNTs/CFX}

The FTIR spectra of porous n- HAp scaffold with a porosity of $10 \%$ (HAP-10)-MWCNTS loaded with CFX for different ratios of MWCNTS are shown in (Figure. 3). FTIR portrays a composition of pure HAP, pure CFX and composite porous n-HAP-10/MWCNTS; these spectra do not differ significantly. The phase composition was also confirmed by the FTIR analysis. There were bands at $569,609,1094,4,1144.55 \mathrm{~cm}^{-1}$ which were assigned as the stretching and bending motion of phosphate in the HAp in addition, a sharp peak at $1047.16 \mathrm{~cm}^{-1}$. Confirming the presence of crystallized HAp. The bands at $3436.53 \mathrm{~cm}^{-1}$ and $630.61 \mathrm{~cm}^{-1}$. Corresponded to the stretching mode of the hydroxyl group of HAp. The spectra also illustrate the stretching modes of carbonate ions and hydroxyl groups that implied the formation of MWCNTs on the HAp matrix. The absorption bands observed in the range of $1300-1650 \mathrm{~cm}^{-1}$ are due to the stretching and bending modes of $\mathrm{C}-\mathrm{O}$ and $\mathrm{P}-\mathrm{O}$ peaks and air carbonate $\left(\mathrm{CO}_{3}\right)^{-2}$. ions, that appear sharper when the MWCNTs increase (because of the high surface area of the MWCNTs). Bands around $2924 \mathrm{~cm}^{-1}$ and $2854 \mathrm{~cm}^{-}$ 1 are due to the asymmetric and symmetric stretching of $\mathrm{C}-\mathrm{H}$ band. It might also confirm the positive effect of nanotubes on improving the quality of hydroxyapatite crystallization[15]. The emergence of characteristic peak at $1702 \mathrm{~cm}-$ 1indicat a good incorporation of CFX in to porous n- HAp-10/MWCNTs[13, 14]. By comparing the spectra (HAp-10 /MWCNTs) with different concentration of MWCNTs powders loaded CFX and pure CFX, the characteristic peaks of CFX were the similar as in the standard chart except a peak at $1702 \mathrm{~cm}^{-1}$. By comparing the

J. Text. Color. Polym. Sci. Vol. 17, No.1 (2020) spectra (HAp-10 /MWCNTs) with different concentration of MWCNTs powders loaded CFX and pure HAp the characteristic peaks of each material are still observable as in standard sample but with an increase in intensity, when the concentration of MWCNTs increase. The peaks from both composite in all samples matched with synthesized pure porous n-HAp pattern.

$X$-ray diffraction of CFX loaded with porous $n-H A p$

X-ray diffraction patterns for porous n-HAp/ ciprofloxacin composites with different porosity $(5 \%, 20 \%)$ obtained by burn out of pore former were investigated. The phase identified was $\mathrm{Ca}_{9.61}(\mathrm{PO} 4)_{5.77}(\mathrm{OH})_{2.29}\left(\left(\mathrm{H}_{2} \mathrm{O}\right)_{1.01} \mathrm{H}_{0.59}\right)$. the ‘ and " value of porous n-HAp is 9.4737 and 6.8863respectively that are close to the lattice parameter of stoichiometric hydroxyapatite nanopaparticles (powder diffraction file ICSD $01-073-2656=9.4737$ and $=8863$ ); XRD profiles of porous n-HAp/ciprofloxacin composites are shown in Fig. 4 did not display any changes in characteristic peaks for porous n- HAp from that of pure HAp, indicating that the ciprofloxacin might be existing in the form of a noncrystalline or in solid solution in the HAp matrix.

XRD of ciprofloxacin loaded with n-porous HAp/ $M W C N T S$

X-ray powder diffraction chart of porous n-HAp/MWCNTS-CFX composite with different ratio of MWCNTs $\left(0.5 \times 10^{-3} \%\right.$ and $\left.3 \times 10^{-3} \%\right)$ are shown in figure 5 . The phase identified was $\mathrm{Ca}_{5}$ $\left(\mathrm{PO}_{4}\right)_{3}(\mathrm{OH})$. The ' ' and ' " value of porous n-HAp are 9.4320 and 6.8810 respectively that are close to the lattice parameter of stoichiometric hydroxyapatite nano particles (powder diffraction 


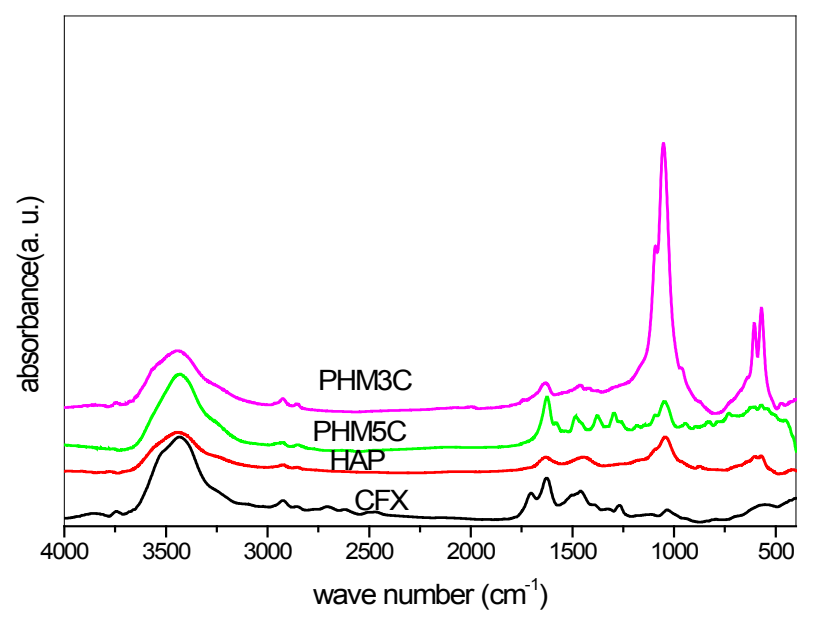

Fig. 3. FTIR spectra of pure ciprofloxacin (CFX), pure HAp and porous hydroxyapatite (HAP-10) /MWCNTs loaded with ciprofloxacin at various MWCNTs ratios (PHM0.5C and PHM3C).

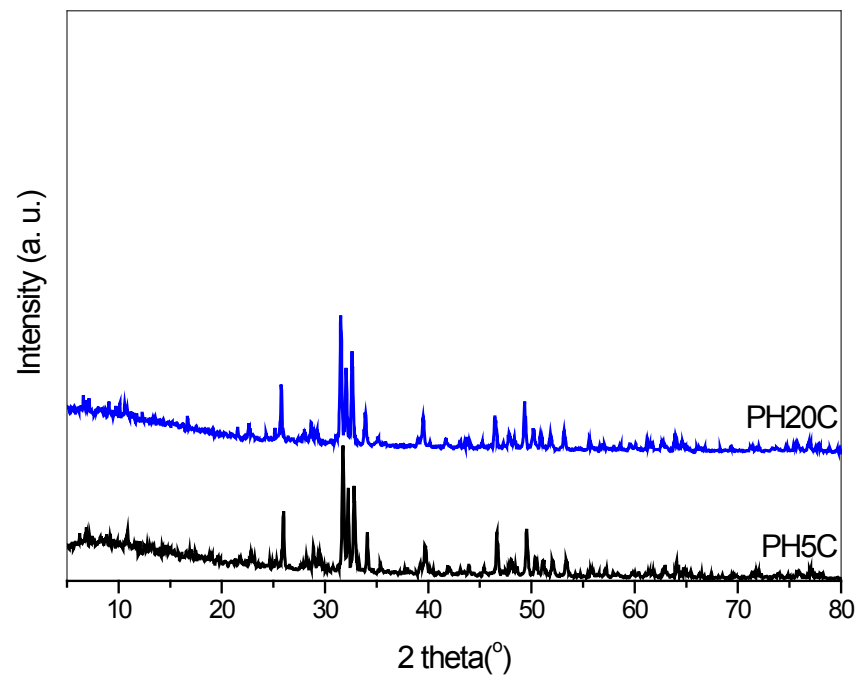

Fig. 4. X-ray spectra of porous hydroxyapatite loaded with ciprofloxacin at various hydroxyapatite ratios (PH5C and PH20C),

file ICSD 01-073-0293 $=9.4320$ and $=6.8810$ ); there was no new absorption peak was exist indicated that no new composite have been formed in the scaffold as a result of the addition of MWCNTs. The mainly peak of graphitic (002) of MWCNTs $\left(2 \theta=26.6^{\circ}\right)[2,16]$ not detected in the X-ray chart patterns of the prepared scaffold. This is due to the minor fraction of the MWCNTs used for enhanced prepared scaffold was difficult to notice within the sensitivity bound of the used tool. The detection of prepared porous n-HApMWCNTs has been distinguished by analyzing the FTIR spectra as shown in Fig. 3. The XRD patterns of CFX loaded with n-porous HAp/ MWCNTs show diffraction peaks with line broadening and high intensities, which confirms the nanosize with crystalline nature[17]. It was clearly demonstrated from the XRD pattern of porous n-HAp/MWCNTs-CFX powders and blank HAp powders did not show any major differences in the diffraction patterns indicating that the antibiotic were present in a non-crystalline form in HAp system.

Scanning Electron Microscope of ciprofloxacin loaded with n-porous HAp/MWCNTs

The SEM morphology of CFX loaded with porous n-HAp-10/MWCNTs composites are shown in Fig.6. This showed a good distribution of CFX with fine hair of MWCNTs imbedded in scaffolds of HAp/MWCNTs and exhibition porous nature of the prepared scaffold, which very favorable for cellular growth chains attached to the HAp crystals. MWCNTs chains are dispersed

J. Text. Color. Polym. Sci. Vol. 17, No.1 (2020) 
in the ceramic matrix with good uniformity. The lattice of HAp with MWCNTs remained mixed together. Porosity in the HAp crystal was also noticed. It proved that MWCNTs have been successfully introduced into the porous HAp matrix and, in addition, that the MWCNTs might still possess their excellent mechanical properties.

\section{Cytotoxicity testing}

Cytotoxicity testing manifested, that the viability of cells BJ1 (normal Skin fibroblast) treated with samples of hydroxyapatite containing MWCNTs at concentrations $\left(3 \times 10^{-3} \%\right)$ were $92.6 \%$. The hydroxyapatite samples containing highest concentrations of MWCNTs showed the cell viability greater than $90 \%$. This indicted that these hydroxyapatite samples were likely not cytotoxic to for fibroblast cells BJ1 did not reach to the degree revealing toxicity[18]. These results suggested that hydroxyapatite containing MWCNTs could be biocompatible material to be applied as body implants [18, 19].

\section{Drug loading in vitro}

As shown in Table 1, the drug was successfully loaded within all the prepared HAp-scaffolds represented with suitable encapsulation efficiencies. As for porous n-HAp formulations, $\mathrm{PH} 5 \mathrm{C}$ and $\mathrm{PH} 20 \mathrm{C}$, it was recognized as the HAp concentrations increase from $5 \%$ in sample PH5C to $20 \%$ as in sample $\mathrm{PH} 20 \mathrm{C}$, it was found that their encapsulation efficiencies percentages increase to be 31.25 and 35 respectively. The same trend was followed by the porous n-HAp-10/MWCNTs formulae, as the encapsulation power increases from 43 to 45 spontaneously, with increasing the concentration of the samples from $0.5 \times 10^{-3}$ in PHM0.5C to $3 \times 10^{-3}$ in PHM3C. Comparatively, it's clearly noticed that $\mathrm{n}-\mathrm{HAp}-10 / \mathrm{MWCNT}$ formulae revealed a higher encapsulation magnitude than the porous n-HAp formulations, which may be explained by the more influential effect of the MWCNTs presence in contrast to its absence in the ordinary porous n-HAp formulations.

\section{Follow-up of the ciprofloxacin release}

It's clearly represented from Fig. 7 that the ciprofloxacin (CFX) release from all the porous n-HAp nanocomposite scaffolds showed a prolonged sustained profiles, which coincide with similar results documented by other related studies. In the first release hours ( first 8 hours), all samples owned a minimum burst effect that reached its lower level in PHM5C sample then ranked as the follows: PH5C then PHM3C, and finally PH20C, indicating that as the concentration of HAp as well as the MWCNTs increase (as in samples PH20C and PHM3C subsequently), the encapsulation of CFX increase and thus the burst release effect increase, on the other hand, the formulae with MWCNTs (PHM0.5C and PHM3C) had lower burst effect than those of n-HAp alone (PH5C and PH20C), although such scaffolds overall burst effect were considered advantageously low. While, from the 24 to 192 hours the CFX release behavior was sustained controlled and didn't exceed $30 \%$, as the CFX release ranking was ranged between $23-30 \%$ in samples PHM5C and PHM3C respectively and between $17-20 \%$ in samples $\mathrm{PH} 5 \mathrm{C}$ and $\mathrm{PH} 20 \mathrm{C}$ respectively, reflecting a similar trend of a direct proportion between drug concentration and release. Such CFX extended behavior during its release from these scaffolds could be an obvious sign for the successful CFX adsorption and linkage within this study porous n-HAp nanocomposite scaffolds. Thus it can be concluded that the antibacterial effect of CFX released from a single dose of these prepared unique scaffolds could last for months with a distinctive lower burst effect indicating a minimum adverse toxic effects with maximum patient compliance.

\section{Conclusion}

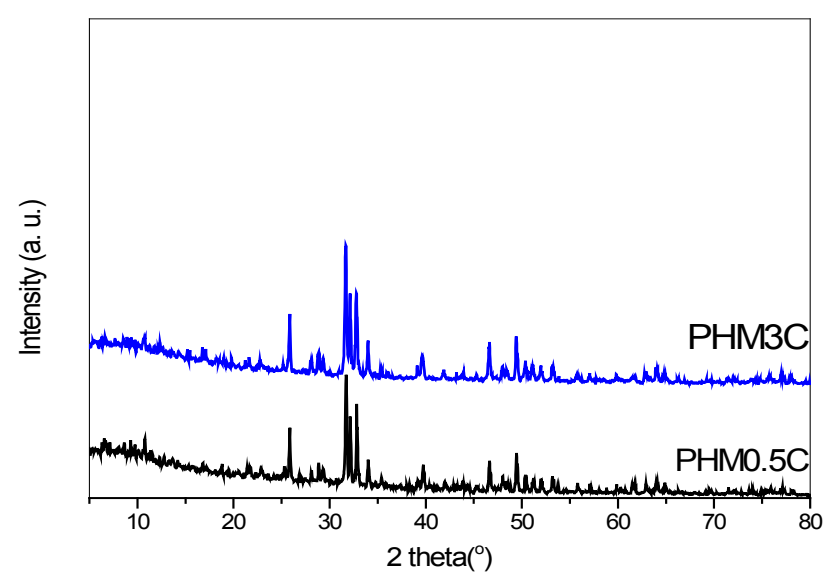

Fig. 5. X-ray spectra of porous hydroxyapatite (HAP-10)/MWCNTs loaded with ciprofloxacin at various MWCNTs ratios (PHM0.5C and PHM3C).

J. Text. Color. Polym. Sci. Vol. 17, No.1 (2020) 

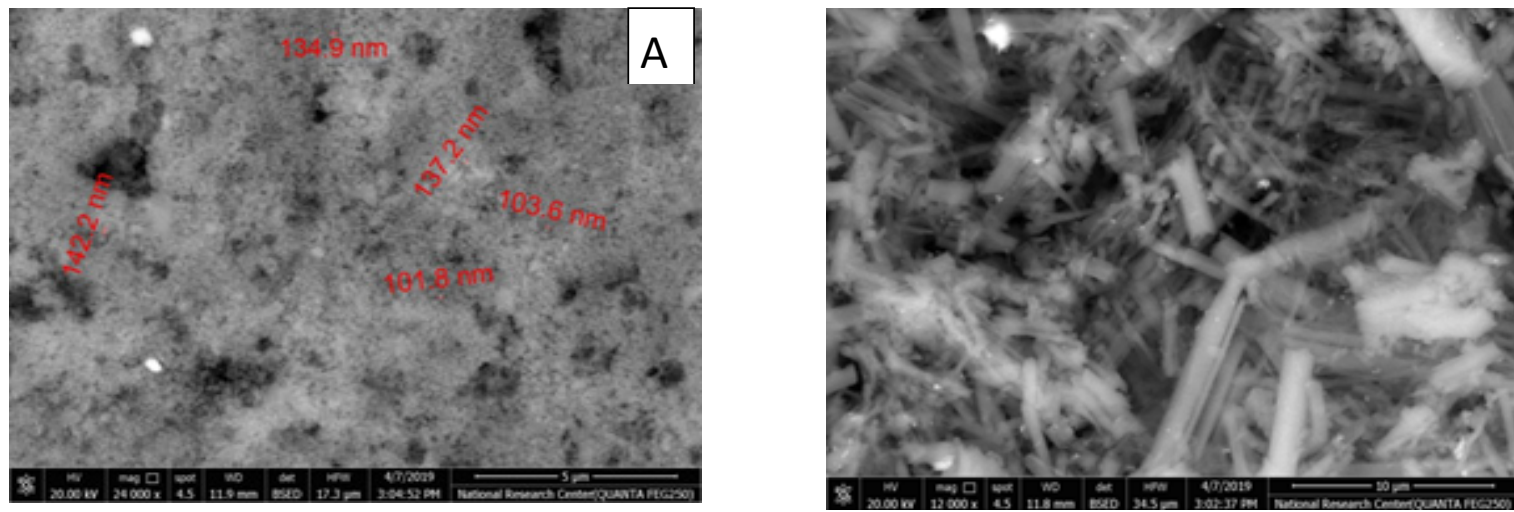

Fig. 6. SEM microscopy porous n-HAP-10/MWCNTS-CFX (A, B) PHM3C.

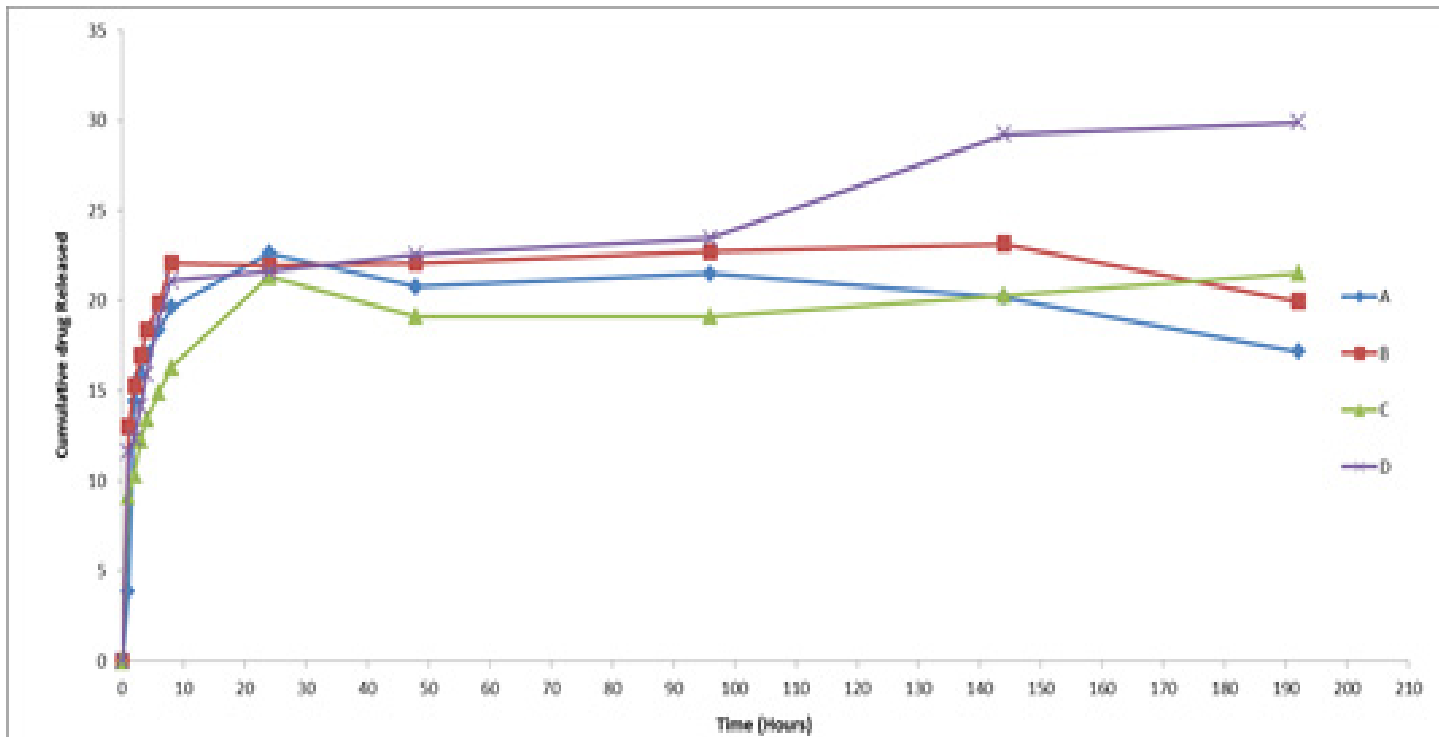

Fig. 7. In vitro release profiles of $\mathrm{CFX}$ porous n-HAp nanocomposite Formula, where $\mathrm{A}=\mathrm{PH} 5 \mathrm{C}, \mathrm{B}=\mathrm{PH20C}, \mathrm{C}=$ PHM0.5C, D= PHM3

TABLE1. Entrapment efficiency percentage of the prepared formulae.

\begin{tabular}{cc}
\hline Sample & Entrapment efficiency \% (EE\%) \\
\hline PH5C & 31.25 \\
PH20C & 35 \\
PHM0.5C & 43 \\
\hline
\end{tabular}


This study succeeded in highlighting a light on a new field of prepared porous n-HAp and porous n- HAp/MWCNTs scaffolds that could encapsulate the CFX with excellency causing a sustained release of the antibacterial action of the drug for a prolonged periods of time, avoiding multiple dosing side effects and unfavorable first pass metabolism and thus could be an effective treatment of bone infectious diseases. The FTIR of the bioceramic scaffold loaded antibiotic (CFX) portrays the peaks from both of composites match well with the standard pure n-HAP and pure CFX. The emergence characteristic peak of CFX at $1702 \mathrm{~cm}^{-1}$ and the absence of new IR beaks confirm that the antibiotic is only dispersed on the HAp surface and are highly masked by the incorporation of the antibiotics by hydrogen bonding to $\mathrm{P}-\mathrm{OH}$ groups with very minute interaction. This confirms that the CFX has no significant effect on the bioceramic scaffold. The XRD did not display any changes in characteristic peaks for porous n-HApCFX and composites of porous n-HAp/MWCNTsCFX, indicating that the antibiotic (CFX) might exist in the form of a noncrystalline. The SEM images showed highly porous in nature that was beneficial for entrapment of the drug and porosity is beneficial in tissue growth and for the flow transport of nutrients and metabolic waste.

\section{References}

1. Loca, D., et al. Porous hydroxyapatite bioceramic scaffolds for drug delivery and bone regeneration. in IOP Conference Series: Materials Science and Engineering. IOP Publishing (2011).

2. Mukherjee, S., et al., Effect of functionalisation of CNT in the preparation of HAp-CNT biocomposites. Ceramics international. 41(3),3766-3774 (2015).

3. Dresselhaus, M., Dresselhaus, G. and Jorio, A. Unusual properties and structure of carbon nanotubes. Annu. Rev. Mater. Res., 34, 247-278 (2004).

4. Zhang, Y., Tan, S. and Yin, Y. C-fibre reinforced hydroxyapatite bioceramics. Ceramics international. 29(1),113-116 (2003).

5. Biswal, S., Preparation of Hydroxyapatite Porous Scaffold. (2010).

6. Hutmacher, D.W., et al., Mechanical properties and cell cultural response of polycaprolactone scaffolds designed and fabricated via fused deposition modeling. Journal of Biomedical Materials Research: An Official Journal of The Society for Biomaterials, The Japanese Society for Biomaterials, and The
Australian Society for Biomaterials and the Korean Society for Biomaterials. 55(2), 203-216 (2001).

7. Castro, C., et al., Two-month ciprofloxacin implants for multibacterial bone infections. European journal of pharmaceutics and biopharmaceutics. 60(3), 401-406 (2005).

8. Amaro Martins, V.C. and G. Goissis, Nonstoichiometric Hydroxyapatite-Anionic Collagen Composite as Support for the Double Sustained Release of Gentamicin and Norfloxacin/Ciprofloxacin. Artificial organs. 24(3), 224-230 (2000).

9. Venkatasubbu, G.D., et al. Hydroxyapatite-alginate nanocomposite as drug delivery matrix for sustained release of ciprofloxacin. Journal of biomedical nanotechnology, 7(6), 759-767 (2011).

10. Yildırım, O., Preparation and characterization of chitosan/calcium phosphate based composite biomaterials. İzmir Institute of Technology, (2004).

11. Sahoo, S., et al., FTIR and XRD investigations of some fluoroquinolones. (2011).

12. Geuli, O., et al., Synthesis, coating, and drug-release of hydroxyapatite nanoparticles loaded with antibiotics. Journal of Materials Chemistry B. 5(38), 7819-7830 (2017).

13. Kumar, N.A. and S. Kumar, Hydroxyapatite-ciprofloxacin minipellets for bone-implant delivery: preparation, characterization, in-vitro drug adsorption and dissolution studies. International Journal of Drug Delivery and Research, 1(1), p. 47-59. (2009).

14. Wu, G., et al., Synthesis, crystal structure, stacking effect and antibacterial studies of a novel quaternary copper (II) complex with quinolone. Molecules. 8(2), 287-296 (2003).

15. Abrishamchian, A., et al., Preparation and characterization of multi-walled carbon nanotube/ hydroxyapatite nanocomposite film dip coated on Ti-6Al-4V by sol-gel method for biomedical applications: an in vitro study. Materials Science and Engineering: C. 33(4), 2002-2010 (2013).

16. Hahn, B.-D., et al., Mechanical and in vitro biological performances of hydroxyapatite-carbon nanotube composite coatings deposited on Ti by aerosol deposition. Acta biomaterialia. 5(8), 3205-3214 (2009).

17. Dhanalakshmi, C., Narayanan, V. and Vijayalakshmi. L. Synthesis, characterization and antimicrobial activity of PVA/hydroxyapatite nanocomposites. in 
International Conference on Nanoscience, Engineering and Technology (ICONSET 2011). IEEE (2011).

18. Sjerobabin, N., et al., Cytotoxicity investigation of a new hydroxyapatite scaffold with improved structural design. Srp Arh Celok Lek. 144(5-6), 280-287 (2016).
19. Mourad, R., et al., Antimicrobial and physicomechanical natures of silver nanoparticles incorporated into silicone-hydrogel films. Contact Lens and Anterior Eye. (2019).

\title{
تحضير مادة مسامية n-HAp مطعمة باستخدام MWCNTs كوسيلة لتوصيل دواء للسيبروفلوكساسين مادة مينين

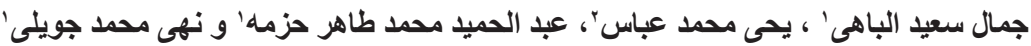

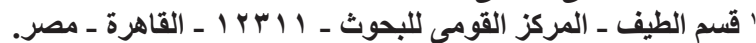

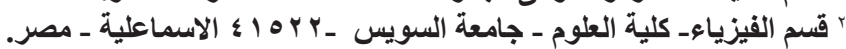

\begin{abstract}
ان الهدف الرئيسى من هذه الدراسة هو تحميل عقار السيبروفلوكساسين على السقالات الحيوية المحضرة من

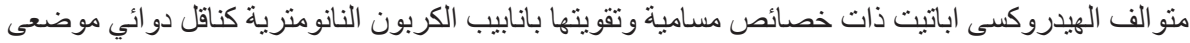

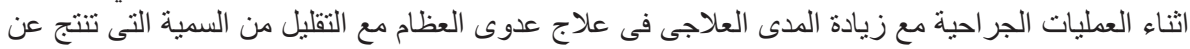

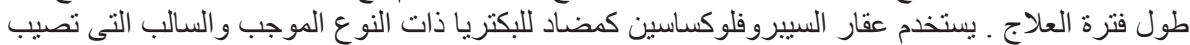

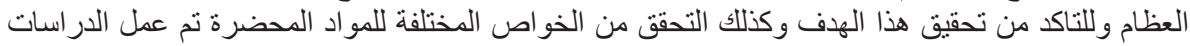

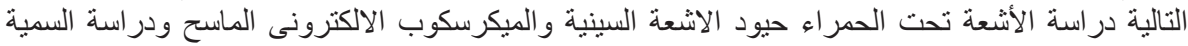

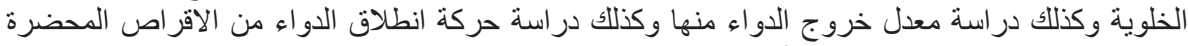

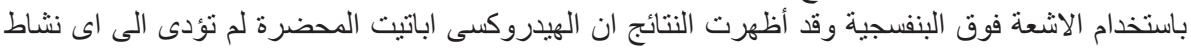

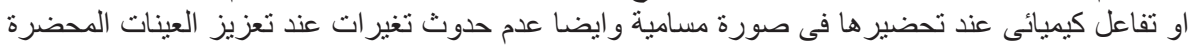

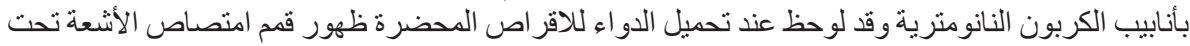

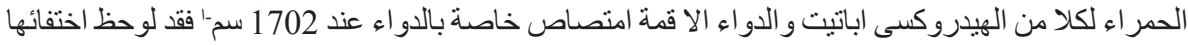

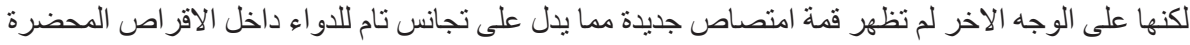

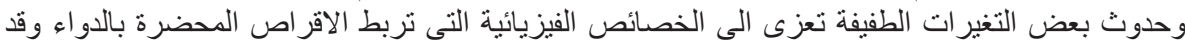

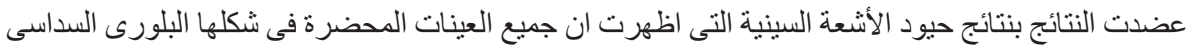

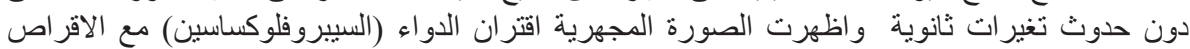

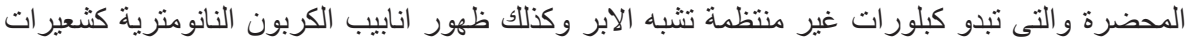
صغيرة ونتيجة لاضافة انابيب الكربون النانومترية فقد تم دراسة السمية الخلوية على التئ الخلايا العظمية الطبيعية

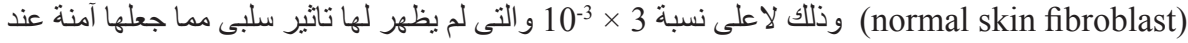

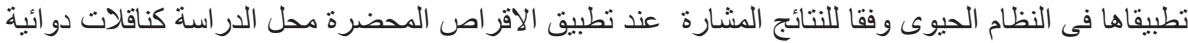

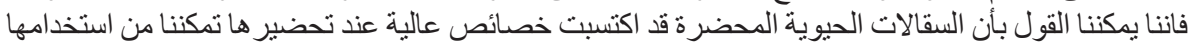

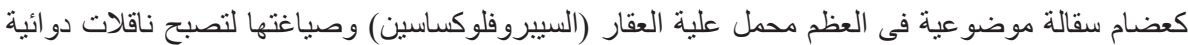
كمضاد للبكتريا و ايضا قادرة على خروج الدو اء بصورة ثابتة ومستمرة تصل الى ثمانية الثنية أيام.
\end{abstract}

